\title{
Declining malaria, rising of dengue and Zika virus: insights for mosquito vector control
}

\author{
Giovanni Benelli ${ }^{1} \cdot$ Heinz Mehlhorn ${ }^{2}$ \\ Received: 6 February 2016 / Accepted: 22 February 2016 / Published online: 2 March 2016 \\ (C) Springer-Verlag Berlin Heidelberg 2016
}

\begin{abstract}
The fight against mosquito-borne diseases is a challenge of huge public health importance. To our mind, 2015 was an extraordinary year for malaria control, due to three hot news: the Nobel Prize to Youyou Tu for the discovery of artemisinin, the development of the first vaccine against Plasmodium falciparum malaria [i.e. RTS,S/AS01 (RTS,S)], and the fall of malaria infection rates worldwide, with special reference to sub-Saharan Africa. However, there are major challenges that still deserve attention, in order to boost malaria prevention and control. Indeed, parasite strains resistant to artemisinin have been detected, and RTS,S vaccine does not offer protection against Plasmodium vivax malaria, which predominates in many countries outside of Africa. Furthermore, the recent outbreaks of Zika virus infections, occurring in South America, Central America and the Caribbean, represent the most recent of four arrivals of important arboviruses in the Western Hemisphere, over the last 20 years. Zika virus follows dengue (which slyly arrived in the hemisphere over decades and became more aggressive in the 1990s), West Nile virus (emerged in 1999) and chikungunya (emerged in 2013). Notably, there are no specific treatments for these arboviruses. The emerging scenario highlights that the effective and ecofriendly control of mosquito vectors, with special reference to highly invasive species such as Aedes aegypti and Aedes albopictus, is crucial. The concrete potential of screening
\end{abstract}

Giovanni Benelli

g.benelli@sssup.it; benelli.giovanni@gmail.com

1 Insect Behaviour Group, Department of Agriculture, Food and Environment, University of Pisa, via del Borghetto 80, 56124 Pisa, Italy

2 Department of Parasitology, Heinrich Heine University, Düsseldorf, Germany plant species as sources of metabolites for parasitological purposes is worthy of attention, as elucidated by the Y. Tu's example. Notably, plant-borne molecules are often effective at few parts per million against Aedes, Ochlerotatus, Anopheles and Culex young instars, can be used for the rapid synthesis of mosquitocidal nanoformulations and even employed to prepare cheap repellents with low human toxicity. In addition, behaviour-based control tools relying to the employ of sound traps and the manipulation of swarming behaviour (i.e. "lure and kill" approach) are discussed. The importance of further research on the chemical cues routing mosquito swarming and mating dynamics is highlighted. Besides radiation, transgenic and symbiont-based mosquito control approaches, an effective option may be the employ of biological control agents of mosquito young instars, in the presence of ultra-low quantities of nanoformulated botanicals, which boost their predation rates.

Keywords Arbovirus - Artemisinin - Biological control · Boosted SIT $\cdot$ Nanosynthesis $\cdot$ Sex pheromones $\cdot$ Sterile insect technique $\cdot$ Sound traps $\cdot$ Swarming behaviour $\cdot$ Vaccine

\section{Towards the decline of malaria burden?}

The fight against mosquito-borne diseases is a challenge of huge public health importance (Jensen and Mehlhorn 2009; Mehlhorn et al. 2012). To our mind, 2015 was an extraordinary year for malaria control, due to three major issues. First, Youyou Tu had won the 2015 Nobel Prize in physiology or medicine, due to the development of the antimalarial drug artemisinin (Fig. 1) (Callaway and Cyranoski 2015). This highlights the key importance of natural product research in the fight against parasites. In the 1960s, within a Chinese national project aimed to discover new tools against malaria, 


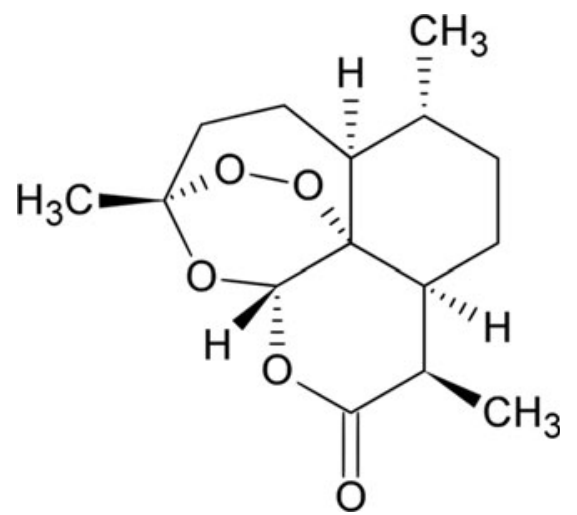

Fig. 1 Artemisinin, discovered by the Nobel Laureate Youyou Tu, and its semi-synthetic derivatives are the drugs showing the most rapid action against $P$. falciparum malaria

Y. Tu and her team screened more than 2000 Chinese herbal remedies to search for drugs with antimalarial activity. The extracts of Artemisia annua were especially effective against Plasmodium parasites, and by 1972, Y. Tu and colleagues had isolated the artemisinin (Tu 2011).

Second, a vaccine that confers partial protection against Plasmodium falciparum in young children has been recently developed (Cohen et al. 2011; WHO 2015a). RTS,S/AS01 (RTS,S) (Mosquirix ${ }^{\mathrm{TM}}$ ) is the result of a partnership between GlaxoSmithKline Biologicals (GSK) and the PATH Malaria Vaccine Initiative (MVI), with support from the Bill \& Melinda Gates Foundation, and from a network of African research centres that performed the studies. Notably, WHO reports that the clinical testing of RTS,S is at least 5-10 years ahead of other candidate malaria vaccines (WHO 2015a).

Third, according to the latest estimates from WHO, between 2000 and 2015, malaria incidence rates (new malaria cases) fell by $37 \%$ globally, and by $42 \%$ in Africa (WHO 2015b). During this same period, malaria mortality rates fell by $60 \%$ globally and by $66 \%$ in the African Region. Since 2000, the malaria mortality rate declined by $85 \%$ in the Southeast Asia Region, by $72 \%$ in the region of the Americas, by $65 \%$ in the Western Pacific Region, and by $64 \%$ in the Eastern Mediterranean Region. For the first time, the European Region reported zero indigenous cases of malaria in 2015. In 2015, malaria killed an estimated 306, 000 under-fives globally, including 292, 000 children in the African region. Between 2000 and 2015, the mortality rate among children under five fell by $65 \%$ worldwide and by $71 \%$ in Africa (White 2015; WHO 2015b).

\section{The rise of dengue, Zika virus and other arboviruses}

Dengue, a viral infection mainly vectored by Aedes mosquitoes, slyly arrived in the Western Hemisphere over decades, then its incidence has grown dramatically from the 1990s. The actual numbers of dengue cases are underreported and many cases are misclassified (WHO 2015c). A recent estimate indicates 390 million dengue infections per year $(95 \%$ credible interval 284-528 million), of which 96 million (67-136 million) manifest clinically (with any severity of disease) (Bhatt et al. 2013). Another study, of the prevalence of dengue, estimates that 3900 million people, in 128 countries, are at risk of infection with dengue viruses (Becker et al. 2012; Brady et al. 2012; Mehlhorn 2012, 2016).

There is no specific treatment for dengue. However, the development of three tetravalent live-attenuated vaccines is in progress (phase II and phase III clinical trials) (WHO 2015c). In addition, recent research highlighted the potential of plant-synthesized nanoparticles as inhibitors of dengue growth (Sujitha et al. 2015; Benelli 2016a). From a mechanistic point of view, green-synthesized silver nanoparticles act as inhibitors of the production of dengue DEN-2 viral envelope (E) protein in Vero cells, and downregulate the expression of dengue viral E gene (Murugan et al. 2015a). However, a certain level of cytotoxicity of the tested nanoparticles has been reported (e.g. about $30 \%$ in cell viability reduction when tested at $50 \mu \mathrm{g} / \mathrm{ml}$. Later on, it has been elucidated that Centroceras clavulatum-synthesized silver nanoparticles tested at $50 \mu \mathrm{g} / \mathrm{ml}$ did not show relevant toxicity against Vero cells, but inhibit DEN-2 viral growth of more than $80 \%$ (Murugan et al. 2016). Once again, this highlights the concrete potential of screening an extensive number of plant species as sources of metabolites for parasitological purposes, with special reference to the potential treatment of arboviral diseases.

Furthermore, the recent outbreaks of Zika virus infection occurring in South America, Central America and the Caribbean, represents the most recent of the four key arrivals of arboviruses in the Western Hemisphere over the last 20 years (Attar 2016; Fauci and Morens 2016). Indeed, Zika virus follows dengue, West Nile virus, which emerged in 1999, and chikungunya, which emerged in 2013 (Morens and Fauci 2014). The Zika virus belongs to the genus Flavivirus. It is mainly vectored by Aedes mosquitoes (Marcondes and Ximenes 2015). These mosquitoes (e.g. Aedes aegypti, Aedes albopictus, Ochlerotatus japonicus, Fig. 2) are constantly spreading over the continents (Becker et al. 2012; Melaun et al. 2015, Figs. 3 and 4). Zika virus was first identified in Uganda in 1947 in Rhesus monkeys, within a monitoring network of sylvatic yellow fever. Later on, it has been identified in humans in 1952, in Uganda and the United Republic of Tanzania (Dick et al. 1952). In latest years, several important outbreaks of Zika virus have been reported from the Pacific (i.e. Yap, 2007; French Polynesia, 2013), as well as from the Americas (Brazil and Colombia, 2015) and Africa (Cape Verde, 2015). Moreover, 13 countries more in the Americas have registered sporadic Zika virus infections, highlighting the rapid geographic expansion of this arbovirus (WHO 2016; Petersen et al. 2015).

Zika symptoms last 2-7 days and are comparable to those characterizing other arbovirus infections, with special reference 


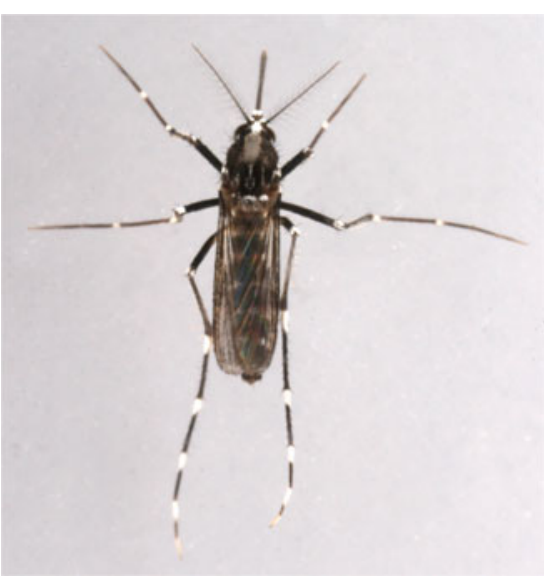

Fig. 2 Macrophoto of an Aedes female

to dengue; symptoms include fever, skin rashes, conjunctivitis, muscle and joint pain, malaise and headache. However, the surveys conducted on the high numbers of cases of Zika virus infections in French Polynesia (2013) and Brazil (2015) highlighted potential neurological and autoimmune complications. During the Zika virus outbreaks in French Polynesia, a concomitant epidemic of 73 cases of Guillain-Barré syndrome and other neurologic conditions was observed in a population of about 270,000 people (Oehler et al. 2014). In Northeast Brazil, during 2015, the increase in Zika virus infections has been reported in close concurrence of an increase in babies born with microcephaly (European Centre for Disease Prevention and Control 2015). WHO (2016) pointed out that further research is urgently needed to shed light on the relationship between these potential complications and Zika virus infections.

Unfortunately, as already known for other arboviruses such as dengue, West Nile and chikungunya, no vaccines or other specific treatments are available, and avoidance of mosquito bites remains the best strategy (WHO 2016). Current prevention tools are represented by the employ of mosquito repellents (Amer and Mehlhorn 2006a, b; Mehlhorn et al. 2005), light-coloured clothes covering as such of the body as possible, and sleeping under mosquito nets (Benelli 2015a). Concerning chemically derived repellents, the number of these products has been considerably reduced by the European Community. Therefore, there are rather few compounds left, including DEET (N,N-diethyl-mtoluamide), IR3535 (3-N-acetyl-N-butylamino-proprionic ethyl ester), icaridin (i.e. Saltidin ${ }^{\circledR}$, 1-piperidine-carboxylic acid 2-2 hydroxyethyl-1methylester), and also an Eucalyptus citriodora derivative (para-menthane-3,8-diol) (Abdel-Ghaffar et al. 2015; Mehlhorn 2016). People living in regions with endemic mosquito borne diseases should synergize these strategies with the reduction or removal of Culicidae breeding sites, as well as with mosquitocidal treatments using chemical or microbiological ovicides, larvicides and pupicides (Amer and Mehlhorn 2006c, d; Semmler et al. 2009; Benelli 2015b). Concerning the employ of synthetic pesticides, particular attention should be given to the development of mosquito-resistant strains, as well as to concerns for human health and the environment (Hemingway and Ranson 2000; Naqqash et al. 2016).

Furthermore, biological control programmes based on the release of larvivorous organisms are frequently not suitable in the majority of urban environments exploited by larvae of some Aedes species, and require further research (Bowatte et al. 2013). Renewed interest has been recently devoted to the potential of sterile insect technique (SIT) for suppression of mosquito vectors, with special reference to the genus Anopheles (Lees et al. 2014; Bourtzis et al. 2016). Interestingly, SIT has been recently combined with auto-dissemination (i.e. adult females contaminated with dissemination stations of juvenile hormone to treat breeding habitats), a technique recently proved very efficient to control Aedes species but that cannot be used at large scales.

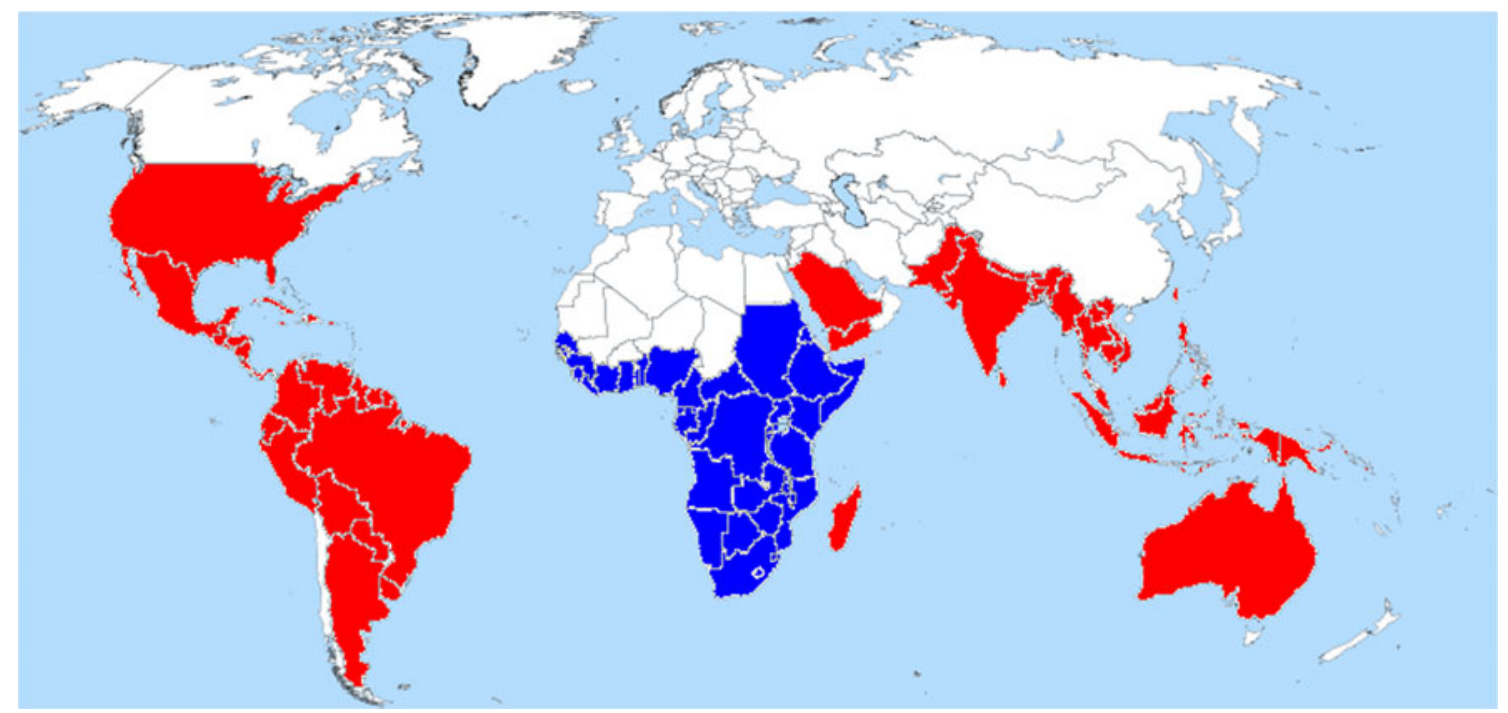

Fig. 3 Worldwide distribution of A. aegypti [blue=countries with native populations; $r e d=$ countries with non-native (established) populations (from Becker et al. 2012)] 


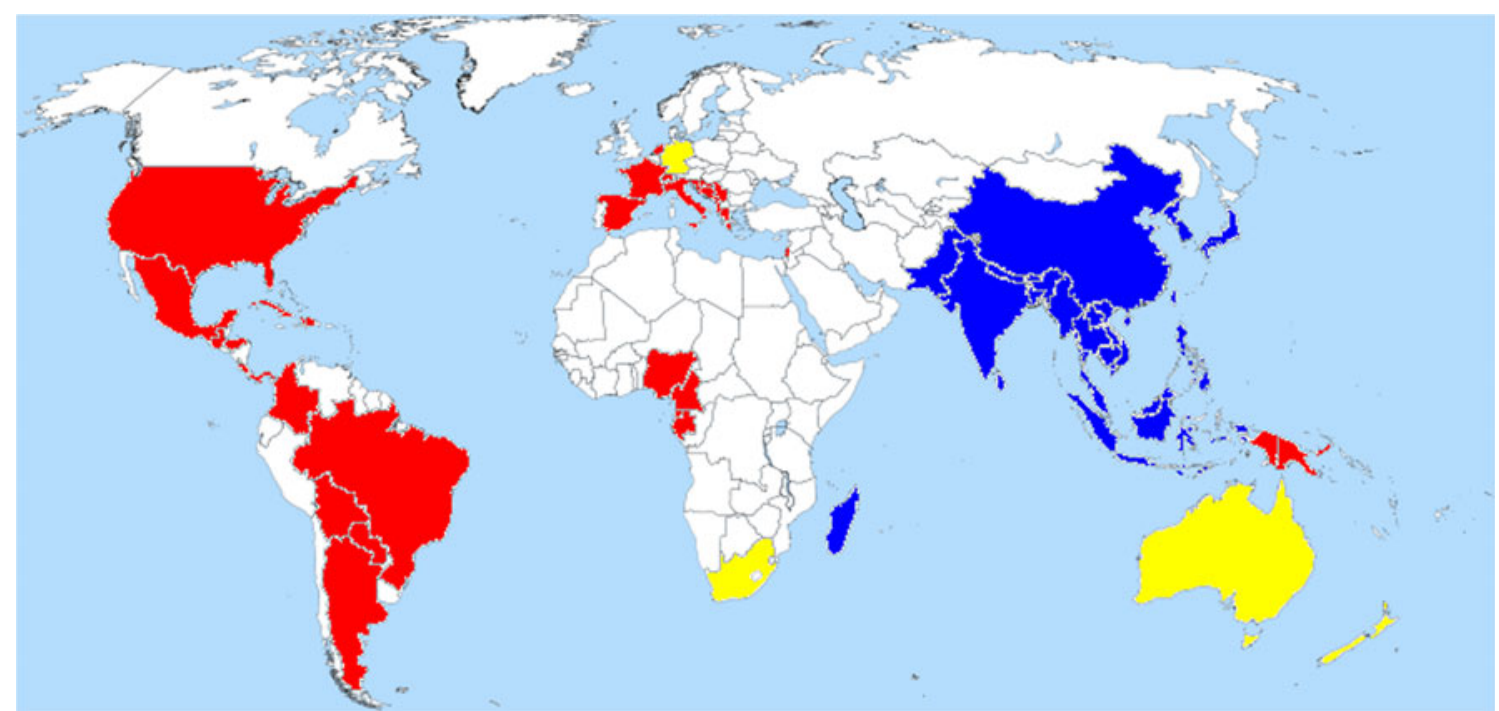

Fig. 4 Worldwide distribution of $A$. (Stegomyia) albopictus [blue=countries with native populations; red=countries with non-native (established) populations; yellow = countries with sporadic occurrence—not established populations (from Becker et al. 2012)]

This has led to formulate a new control concept, named "boosted SIT" that might enable the area-wide eradication of mosquitoes and other vectors of medical and veterinary importance (Bouyer and Lefrançois 2014). Lees et al. (2015) also highlighted that, until perfect sexing mechanisms exist, a combination of Wolbachia-induced phenotypes, such as cytoplasmic incompatibility and pathogen interference, and irradiation may prove to be the safest solution for population suppression.

\section{Eco-friendly control of malaria and arbovirus vectors: a crucial issue}

Despite the exciting research news mentioned above, both the malaria and arbovirus control will be difficult in the future. Here, we focus on at least three main limitations that will maintain the management of mosquito-borne diseases challenging in the future. First, it should be pointed out that the RTS,S/AS01 (RTS,S) vaccine does not offer protection against Plasmodium vivax malaria, which predominates in many countries outside of Africa (Figs. 5 and 6) (WHO 2015a; Carlton et al. 2008a, b). This vaccine is being assessed as a complementary malaria control tool that could potentially be added to, and not replace, the core package of proven malaria preventive, diagnostic and treatment measures (see WHO 2015a). Second, artemisininresistant Plasmodium has been detected, and the WHO Global Malaria Programme issues regular updates about the status of artemisinin resistance in affected countries (WHO 2015d). Third, a number of malaria prevention and control tools currently available are quite expensive, thus not readily available for poor and marginalized populations in tropical and subtropical areas worldwide (Benelli 2015a).

Arbovirus vector management also has to face significant challenges, due to the peculiar traits of Aedes vectors, which have huge physiological and ecological plasticity, including the ability to exploit small water reservoirs as breeding habitats (Benelli 2015a). Among them, the Asian tiger mosquito, A. albopictus (Skuse), deserves a standing-alone focus. Indeed, this is currently the most invasive mosquito worldwide (Benedict et al. 2007), and its medical and veterinary importance is magnified by its daytime human-biting behaviour and the ability to vector, besides dengue, a wide number of other viruses, including La Crosse encephalitis, West Nile and chikungunya (Bonizzoni et al. 2013). In addition, the possibility that the Zika virus may adapt to exploit $A$. albopictus as a vector is a noteworthy concern, since it has been previously highlighted that other arboviruses transmitted by Culicidae have adapted to domestic animals, including

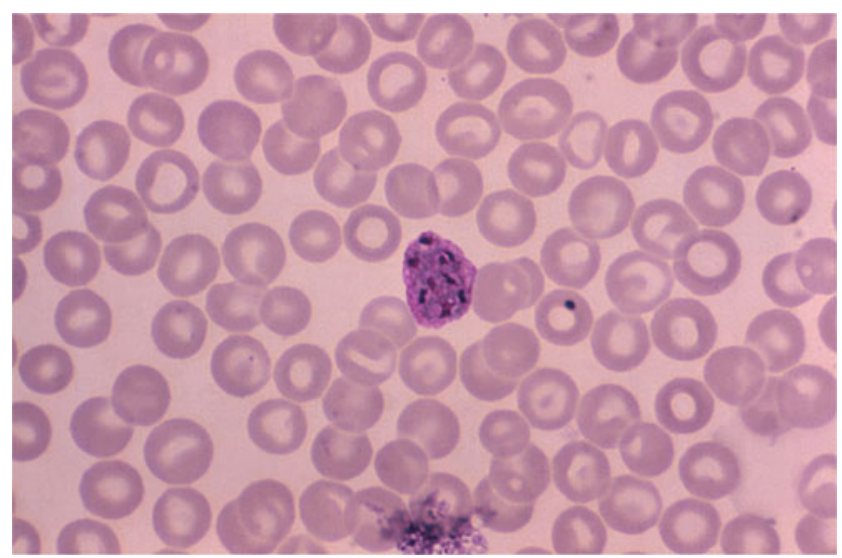

Fig. 5 The malaria vaccine RTS,S/AS01 (RTS,S)] has been developed to fight $P$. falciparum, while it does not offer protection against $P$. vivax, which predominates in many countries outside of Africa. Here, magnified $\times 1000$, a Giemsa-stained photomicrograph revealing ultrastructural morphology exhibited by an immature $P$. vivax schizont (courtesy of Public Health Image Library, Centers for Disease Control and Prevention, Dr. Mae Melvin) 


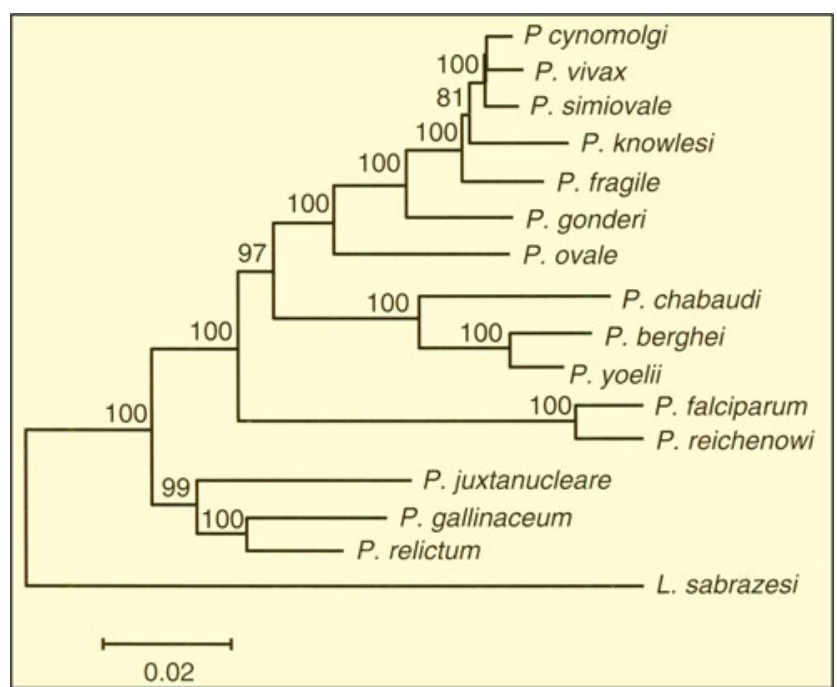

Fig. 6 Dendrogram of the relationship of Plasmodium species based on the mitochondrial genome. The limiting line below shows the number of nucleotid substitutions. The bird parasite Leucocytozoon sabrazesi was selected as an "outgroup" (from Carlton et al. 2008a, b)

horses (e.g. Venezuelan equine encephalitis) and pigs (e.g. Japanese encephalitis), to other vertebrate hosts, as well as to non-Aedes mosquitoes found in different areas of human habitation, as occurred for West Nile virus (Fauci and Morens 2016).

\section{Plants and fungi as a reservoir of mosquitocidal products?}

The emerging scenario highlights that the eco-friendly control of mosquito vectors, with special reference to highly invasive species, is crucial (Benelli 2015a). In particular, the concrete potential of screening plants and fungi as sources of metabolites for parasitological purposes, is worthy of attention, as elucidated by the Y. Tu's example. Notably, plant-borne molecules are often effective at few parts per million against Aedes, Anopheles and Culex young instars (see Benelli 2015b and Pavela 2015 for recent reviews) can be used for the rapid synthesis of mosquitocidal nanoformulations (Benelli 2016b) and even employed to prepare cheap repellents with low human toxicity (Semmler et al. 2009). Besides radiation, transgenic and symbiont-based control approaches (e.g. Wiwatanaratanabutr et al. 2010; Oliva et al. 2012; Moretti and Calvitti 2013; see Bourtzis et al. 2016 for a dedicated review), an effective option readily available in tropical and subtropical areas worldwide may be the employ of biological control agents of Culicidae young instars, in the presence of ultra-low quantities of nanoformulated botanicals, which boost their predation rates (e.g. Murugan et al. 2015b, c; Subramaniam et al. 2016).

\section{Behaviour-based control tools}

As regards behaviour-based control tools, the importance of basic knowledge concerning the Culicidae mating ecology, with special reference to their sexual chemical ecology, has been widely underestimated in the past (Benelli 2015a). Indeed, detailed information on the mating ecology of mosquito vectors is of interest to improve the success of mosquito control programmes in a number of different scenarios. First, this information is crucial for any control programme against mosquito vectors of medical and veterinary importance, since it is widely known that the success of SIT is largely dependent to the ability of sterile males to compete for mates with wild ones in the field (Lees et al. 2014, 2015; Oliva et al. 2013, 2014).

Second, behavioural knowledge about mosquito swarming and mating behaviour may be used to perform comparisons of courtship and mating ethograms among different vector species and strains, allowing monitoring and optimisation of quality of mass-reared males (i.e. sexual competitiveness and mating success) over time in SIT programmes and "boosted SIT" programmes, as well as to monitor the mating performances in mass-reared Wolbachia-induced phenotypes (Benelli 2015a, c). As a general trend, quantitative analyses of mating ethograms in Culicidae are rare, and mainly focuses on the elaborate courtships found in the genus Sabethes (Zsemlye et al. 2005; South and Arnqvist 2008, 2009, 2011) and Wyeomyia (Philips et al. 1996). In particular, the majority of the studies focused on the sexual behaviour of medically important Aedes species focused on comparisons of insemination ability in sterilized and wild males (e.g. Balestrino et al. 2010; Wiwatanaratanabutr et al. 2010; Boyer et al. 2011; Oliva et al. 2012; Bellini et al. 2013; Hamady et al. 2013; Moretti and Calvitti 2013; Madakacherry et al. 2014), without behavioural quantification of courtship and mating events (but see Oliva et al. 2013; Benelli 2015c; Benelli et al. 2015). Notably, limited information is also available on the potential molecules mediating aggregation and mating dynamics in mosquitoes (Cabrera and Jaffe 2007; Fawaz et al. 2014; Pitts et al. 2014).

Third, the possibilities to control mosquito populations by using sound traps deserve further attention (Diabate and Tripet 2015). This fascinating and eco-friendly control method was firstly experimented in Cuba in 1949 against Anopheles albimanus, where the use of a sound trap allowed the collection of an elevate number of males (Kahn and Offenhauser 1949). Later on, similar approaches led to successful removal of Culex tarsalis males, reducing female insemination (Kanda et al. 1988), and diminished the quote of Culex tritaeniorhynchus paorus females (Ikeshoji 1981). However, even if it has been claimed that the partial overlapping of wing-beat frequencies may potentially be advantageous, attracting more than a single mosquito species, it should be pointed out that there are at least two major shortcomings that reduce the field success of sound traps against mosquitoes (Diabate and Tripet 2015, see also Cator and Harrington 2010). Indeed, the design and production of sound traps able to attract mosquitoes from long distances, with proper 
amplification features, is quite difficult. Furthermore, to achieve effective results, the traps should be placed in sites, which are close to the best one selected by mosquito vectors for swarming. To allow this, novel and efficacious methods of identification of swarming sites, in particularly for anophelines, are urgently required (Diabate and Tripet 2015).

Fourth, the "lure and kill" approach, already used with success against a number of arthropod pests (Benelli et al. 2014), has been recently revisited to apply also in the fight against mosquito vectors (Diabate and Tripet 2015), with special reference to the genus Anopheles. Indeed, for anophelines, visual stimuli are probably the most important used to converge in a swarming site (Charlwood et al. 2002; Diabate et al. 2011; see also Dabiré et al. 2014). Consequently, recent research has highlighted the possibility to disrupt or enhance swarms, manipulating artificial markers. These efforts may lead to create "kill zones" (e.g. within or in close proximity of villages) where high numbers of mosquitoes can be attracted and killed. To gain further applied interest, this novel tool requires the development of rapid and cheap methods of identification of swarming sites, which are currently ongoing (see Diabate and Tripet 2015 for a dedicated review).

As a final remark, further research on the exact nature of chemical cues routing mate searching and choice dynamics in mosquito vectors is required, as well as behavioural studies dissecting the relative importance of visual (with special reference to swarming landmarks), vibrational, olfactory and tactile cues perceived during swarming and mate recognition (Benelli 2015a).

Acknowledgments We would like to thank A. Canale, M. Nicoletti and K. Murugan for helpful discussions on the topic. G. Benelli is supported by PROAPI (PRAF 2015) and University of Pisa, Department of Agriculture, Food and Environment (Grant ID: COFIN2015_22). Funders had no role in the study design, data collection and analysis, decision to publish or preparation of the manuscript.

\section{Compliance with ethical standards}

Conflict of interests The authors declare that they have no conflict of interest. Heinz Mehlhorn and Giovanni Benelli are Editor in Chief and Editorial Board Member of Parasitology Research, respectively. This does not alter the authors' adherence to all the Parasitology Research policies on sharing data and materials.

\section{References}

Abdel-Ghaffar F, Al-Quraishy S, Mehlhorn H (2015) Length of tick repellency depends on formulation of the repellent compound (icaridin $=$ Saltidin $^{\circledR}$ ): tests on Ixodes persulcatus and Ixodes ricinus placed on hands and clothes. Parasitol Res 114:3041-3045

Amer A, Mehlhorn H (2006a) Repellency effect of forty-one essential oils against Aedes, Anopheles and Culex mosquitoes. Parasitol Res 99: $478-490$
Amer A, Mehlhorn H (2006b) The sensilla of Aedes and Anopheles mosquitoes and their importance in repellency. Parasitol Res 99: 491-499

Amer A, Mehlhorn H (2006c) Larvicidal effects of various essential oils against Aedes, Anopheles, and Culex larvae (Diptera, Culicidae). Parasitol Res 99:466-472

Amer A, Mehlhorn H (2006d) Persistency of larvicidal effects of plant oil extracts under different storage conditions. Parasitol Res 99:473477

Attar N (2016) ZIKA virus circulates in new regions. Nat Rev Microbiol 14:62. doi:10.1038/nrmicro.2015.28

Balestrino F, Medici A, Candini G, Carrieri M, Maccagnani B, Calvitti M, Maini S, Bellini R (2010) $\gamma$ ray dosimetry and mating capacity studies in the laboratory on Aedes albopictus males. J Med Entomol 47:581-591

Becker N, Pluskota B, Kaiser A, Schaffner F (2012) Exotic mosquitoes conquer the world. In: Mehlhorn H (ed) (2012) Arthropods as vectors of emerging diseases. Parasitol Res Monographs Vol 3, pp 31-60

Bellini R, Balestrino F, Medici A, Gentile G, Veronesi R, Carrieri M (2013) Mating competitiveness of Aedes albopictus radio-sterilized males in large enclosures explosed to natural conditions. J Med Entomol 50:94-102

Benedict MQ, Levine RS, Hawley WA, Lounibos LP (2007) Spread of the tiger: global risk of invasion by the mosquito Aedes albopictus. Vector Borne Zoonotic Dis 7:76-85

Benelli G (2015a) Research in mosquito control: current challenges for a brighter future. Parasitol Res 114:2801-2805

Benelli G (2015b) Plant-borne ovicides in the fight against mosquito vectors of medical and veterinary importance: a systematic review. Parasitol Res 114:3201-3212

Benelli G (2015c) The best time to have sex: mating behaviour and effect of daylight time on male sexual competitiveness in the Asian tiger mosquito, Aedes albopictus (Diptera: Culicidae). Parasitol Res 114: 887-894

Benelli G (2016a) Plant-mediated synthesis of nanoparticles: a newer and safer tool against mosquito-borne diseases? Asia Pacif J Trop Biomed. doi:10.1016/j.apjtb.2015.10.015

Benelli G (2016b) Plant-mediated biosynthesis of nanoparticles as an emerging tool against mosquitoes of medical and veterinary importance: a review. Parasitol Res 115:23-34

Benelli G, Daane KM, Canale A, Niu CY, Messing RH, Vargas RI (2014) Sexual communication and related behaviours in Tephritidae: current knowledge and potential applications for integrated pest management. J Pest Sci 87:385-405

Benelli G, Romano D, Messing RH, Canale A (2015) First report of behavioural lateralisation in mosquitoes: right-biased kicking behaviour against males in females of the Asian tiger mosquito, Aedes albopictus. Parasitol Res 114:1613-1617

Bhatt S, Gething PW, Brady OJ, Messina JP, Farlow AW, Moyes CL et al (2013) The global distribution and burden of dengue. Nature 496: 504-507

Bonizzoni M, Gasperi G, Chen X, James A (2013) The invasive mosquito species Aedes albopictus: current knowledge and future perspectives. Trends Parasitol 29:460-468

Bourtzis K, Lees RS, Hendrichs J, Marc JB, Vreysen MJB (2016) More than one rabbit out of the hat: Radiation, transgenic and symbiontbased approaches for sustainable management of mosquito and tsetse fly populations. Acta Trop. doi:10.1016/j.actatropica.2016. 01.009

Bouyer J, Lefrançois T (2014) Boosting the sterile insect technique to control mosquitoes. Trends Parasitol 30:271-273

Bowatte G, Perera P, Senevirathne G, Meegaskumbura S, Meegaskumbura M (2013) Tadpoles as dengue mosquito (Aedes aegypti) egg predators. Biol Control 67:469-474 
Boyer S, Gilles J, Meracienne D, Lemperiere G, Fontenille D (2011) Sexual performance of male mosquito Aedes albopictus. Med Vet Entomol 25:454-459

Brady OJ, Gething PW, Bhatt S, Messina JP, Brownstein JS, Hoen AG et al (2012) Refining the global spatial limits of dengue virus transmission by evidence-based consensus. PLoS Negl Trop Dis 6, e1760

Cabrera M, Jaffe K (2007) An aggregation pheromone modulates lekking behavior in the vector mosquito Aedes aegypti (Diptera: Culicidae). J Am Mosq Control Assoc 23:1-10

Callaway E, Cyranoski D (2015) Anti-parasite drugs sweep Nobel prize in medicine 2015. Nature 526(7572):174-175

Carlton JM, Escalanta AA, Neatsey D, Volkmann SK (2008a) Comparative evolutionary genomics of human malaria parasites. Trends Parasitol 24:545-550

Carlton JM, Adams JH, Silva JC, Bidwell SL, Corenzi H et al (2008b) Comparative genomics of the neglected human malaria parasite Plasmodium vivax. Nature 455:757-763

Cator LJ, Harrington LC (2010) The harmonic convergence of fathers predicts the mating success of sons in Aedes aegypti. Anim Behav 82:627-633

Charlwood JD, Pinto J, Sousa CA, Ferreira C, Do Rosario VE (2002) Male size does not affect mating success of Anopheles gambiae in São Tomé. Med Vet Entomol 16:109-111

Cohen J, Benns S, Vekemans J, Leach A, Schnermann L (2011) Development of the RTS, S/AS vaccine candidate from concept to phase III. In: Mehlhorn H (ed) (2011) Progress in parasitology. Parasitol Res Monographs Vol 2, pp 121-134

Dabiré KR, Sawadogo PS, Hien DF, Maiga H, Millogo A, Baldet T, Simard F, Gouagna L-C, Diabate A, Gibson G, Lees RS, Gilles JRL (2014) Occurrence of natural Anopheles arabiensis swarms in an urban area of Bobo-Dioulasso city, Burkina Faso, West Africa. Acta Trop 132S:S35-S41

Diabate A, Tripet F (2015) Targeting male mosquito mating behaviour for malaria control. Parasit Vector 8:347

Diabate A, Yaro AS, Dao A, Diallo M, Huestis DL, Lehmann T (2011) Spatial distribution and male mating success of Anopheles gambiae swarms. BMC Evol Biol 11:184

Dick GW, Kitchen SF, Haddow AJ (1952) Zika virus. I. Isolations and serological specificity. Trans R Soc Trop Med Hyg 46:509-520

European Centre for Disease Prevention and Control (2015) Microcephaly in Brazil potentially linked to the Zika virus epidemic: ECDC assesses the risk. Solna, Sweden: European Centre for Disease Prevention and Control, November 25, (http://ecdc. europa.eu/en/press/news/ layouts/forms/News DispForm.aspx? I D $=1329 \& \mathrm{~L}$ is t $=8 \overline{\mathrm{d}} \mathrm{b} 7286 \mathrm{c}-\mathrm{fe} 2 \mathrm{~d}-476 \mathrm{c}-9133-$ $18 \mathrm{ff} 4 \mathrm{cb} 1 \mathrm{~b} 568 \&$ Source $=\mathrm{http} \% 3 \mathrm{~A} \% 2 \mathrm{~F} \% 2 \mathrm{Fecdc}$.europa.eu $\% 2 \mathrm{Fen} \%$ 2FPages\%2Fhome.aspx)

Fauci AS, Morens DM (2016) Zika virus in the Americas-yet another arbovirus threat. N Engl J Med. doi:10.1056/NEJMp1600297

Fawaz EY, Allan SA, Bernier UR, Obenauer PJ, Diclaro JW II (2014) Swarming mechanisms in the yellow fever mosquito: aggregation pheromones are involved in the mating behaviour of Aedes aegypti. J Vector Ecol 39:347-354

Hamady D, Ruslan NB, Ahmad AH, Rawi CSM, Hamad H, Satho Tet al. (2013) Colonized Aedes albopictus and its sexual performances in the wild: implications for SIT technology and containment. Parasit Vectors 6:206

Hemingway J, Ranson H (2000) Insecticide resistance in insect vectors of human disease. Annu Rev Entomol 45:371-391

Ikeshoji T (1981) Acoustic attraction of male mosquitoes in a cage. Med Entomol Zool 32:7-15

Jensen M, Mehlhorn H (2009) Seventy-five years of Resochin ${ }^{\circledR}$ in the fight against malaria. Parasitol Res 105:609-627

Kahn MC, Offenhauser W Jr (1949) The first field tests of recorded mosquito sounds used for mosquito destruction. Am J Trop Med Hyg 29:811-825
Kanda T, Loong KP, Chiang GL, Cheong WH, Lim TW (1988) Field study on sound trapping and the development of trapping method for both sexes of Mansonia in Malaysia. Trop Biomed 5:37-42

Lees RS, Knols B, Bellini R, Benedict MQ, Bheecarry A, Bossin HC et al (2014) Review: improving our knowledge of male mosquito biology in relation to genetic control programmes. Acta Trop 132S:S2S11

Lees RS, Gilles JRL, Hendrichs J, Vreysen MJB, Bourtzis K (2015) Back to the future: the sterile insect technique against mosquito disease vectors. Curr Opin Insect Sci 10:156-162

Madakacherry O, Lees RS, Gilles JRL (2014) Aedes albopictus (Skuse) males in laboratory and semi-field cages: release ratios and mating competitiveness. Acta Trop 132S:124-129

Marcondes CB, Ximenes MF (2015) Zika virus in Brazil and the danger of infestation by Aedes (Stegomyia) mosquitoes. Rev Soc Bras Med Trop. doi:10.1590/0037-8682-0220-2015

Mehlhorn H (ed) (2012) Arthropods as vectors of emerging diseases. Parasitol Res Monographs Vol 3, Springer, Heidelberg

Mehlhorn H (ed) (2016) Nanoparticles in the fight against parasites. Parasitol Res Monographs Vol 8, Springer, Berlin, New York

Mehlhorn $\mathrm{H}$ et al (2005) Extract of the seeds of the plant Vitex agnus castus proven to be highly efficacious as a repellent against ticks, fleas, mosquitoes and biting flies. Parasitol Res 95:363-365

Mehlhorn H, Al-Rasheid KA, Al-Quraishy S, Abdel-Ghaffar F (2012) Research and increase of expertise in arachno-entomology are urgently needed. Parasitol Res 110:259-265

Melaun C, Werblow A, Cunze S, Zotzmann S, Koch LK, Mehlhorn H et al (2015) Modeling of the putative distribution of the arbovirus vector Ochlerotatus japonicus japonicus in Germany. Parasitol Res 114:1051-1061

Morens DM, Fauci AS (2014) Chikungunya at the door — déjà vu all over again? N Engl J Med 371:885-887

Moretti R, Calvitti M (2013) Male mating performance and cytoplasmic incompatibility in a $w$ Pip Wolbachia trans-infected line of Aedes albopictus (Stegomyia albopicta). Med Vet Entomol 27:377-386

Murugan K, Dinesh D, Paulpandi M, Althbyani AD, Subramaniam J, Madhiyazhagan P et al (2015a) Nanoparticles in the fight against mosquito-borne diseases: bioactivity of Bruguiera cylindrica-synthesized nanoparticles against dengue virus DEN-2 (in vitro) and its mosquito vector Aedes aegypti (Diptera: Culicidae). Parasitol Res $114: 4349-61$

Murugan K, Benelli G, Panneerselvam C, Subramaniam J, Jeyalalitha T, Dinesh D, Nicoletti M, Hwang JS, Suresh U, Madhiyazhagan P (2015b) Cymbopogon citratus-synthesized gold nanoparticles boost the predation efficiency of copepod Mesocyclops aspericornis against malaria and dengue mosquitoes. Exp Parasitol 153:129-138

Murugan K, Priyanka V, Dinesh D, Madhiyazhagan P, Panneerselvam C, Subramaniam J, Suresh U, Chandramohan B, Roni M, Nicoletti M, Alarfaj AA, Higuchi A, Munusamy MA, Khater HF, Messing RH, Benelli G (2015c) Enhanced predation by Asian bullfrog tadpoles, Hoplobatrachus tigerinus, against the dengue vector Aedes aegypti in an aquatic environment treated with mosquitocidal nanoparticles. Parasitol Res 114:3601-3610

Murugan K, Aruna P, Panneerselvam C, Madhiyazhagan P, Paulpandi M, Subramaniam J et al (2016) Fighting arboviral diseases: low toxicity on mammalian cells, dengue growth inhibition (in vitro) and mosquitocidal activity of Centroceras clavulatum-synthesized silver nanoparticles. Parasitol Res 115:651-662

Naqqash MN, Gökçe A, Bakhsh A, Salim M (2016) Insecticide resistance and its molecular basis in urban insect pests. Parasitol Res. doi:10. 1007/s00436-015-4898-9

Oehler E, Watrin L, Larre P, Leparc-Goffart, Lastère S, Valour F, Baudoulin L, Mallet HP, Musso D, Ghawche F (2014) Zika virus infection complicated by Guillain-Barré syndrome - case report, French Polynesia. Euro Surveill 19(9) 
Oliva CF, Jacquet M, Gilles J, Lemperiere G, Maquart PO, Quilici S, Schooneman F, Vreysen MJB, Boyer S (2012) The sterile insect technique for controlling populations of Aedes albopictus (Diptera: Culicidae) on Reunion Island: mating vigour of sterilized males. PLoS ONE 7, e49414

Oliva CF, Damiens D, Vreysen MJB, Lemperière G, Gilles J (2013) Reproductive strategies of Aedes albopictus (Diptera: Culicidae) and implications for the sterile insect technique. PLoS ONE 8, e78884

Oliva CF, Damiens D, Benedict MQ (2014) Male reproductive biology of Aedes mosquitoes. Acta Trop 132S:S512-S519

Pavela R (2015) Essential oils for the development of eco-friendly mosquito larvicides: a review. Ind Crop Prod 76:174-187

Petersen E, Wilson ME, Touch S, McCloskey B, Mwaba P et al (2015) Unexpected and rapid spread of Zika virus in the Americas - implications for public health preparedness for mass gatherings at the 2016 Brazil Olympic Games. Int J Infect Dis 44:11-15

Philips KT, Hancock RG, Foster WA (1996) Epigamic display and unique mating position in Wyeomyia arthrostigma (Diptera: Culicidae). J Insect Behav 9:739-753

Pitts RJ, Mozūraitis R, Gauvin-Bialecki A, Lempérière G (2014) The roles of kairomones, synomones and pheromones in the chemically-mediated behaviour of male mosquitoes. Acta Trop 132S:S26-S34

Semmler M, Abdel-Ghaffar F, Al-Rasheid KAS, Mehlhorn H (2009) Nature helps: from research to products against blood sucking arthropods. Parasitol Res 105:1483-1487

South SH, Arnqvist G (2008) Evidence of monandry in a mosquito (Sabethes cyaneus) with elaborate ornaments in both sexes. J Insect Behav 21:451-459

South SH, Arnqvist G (2009) Male mating costs in a polygynous mosquito with ornaments expressed in both sexes. Proc R Soc B 276: $3671-3678$
South SH, Arnqvist G (2011) Male, but not female, preference for an ornament expressed in both sexes of the polygynous mosquito Sabethes cyaneus. Anim Behav 81:645-651

Subramaniam J, Murugan K, Panneerselvam C, Kovendan K, Madhiyazhagan P, Dinesh D, Mahesh Kumar P, Chandramohan B, Suresh U, Rajaganesh R, Saleh Alsalhi M, Devanesan S, Nicoletti M, Canale A, Benelli G (2016) Multipurpose effectiveness of Couroupita guianensis-synthesized gold nanoparticles: high antiplasmodial potential, field efficacy against malaria vectors and synergy with Aplocheilus lineatus predators. Environ Sci Poll Res. doi:10.1007/s11356-015-6007-0

Sujitha V, Murugan K, Paulpandi M, Panneerselvam C, Suresh U, Roni $M$ et al (2015) Green synthesized silver nanoparticles as a novel control tool against dengue virus (DEN-2) and its primary vector Aedes aegypti. Parasitol Res 114:3315-25

Tu Y (2011) The discovery of artemisinin (qinghaosu) and gifts from Chinese medicine. Nat Med 17:1217-1220

White NJ (2015) Declining malaria transmission and pregnancy outcomes in Southern Mozambique. N Engl J Med 373:1670-1671

WHO (2015a) Background brief: malaria vaccine RTS,S/AS01. Updated 23 October 2015

WHO (2015b) Fact Sheet: World Malaria Report 2015. Updated 9 December 2015

WHO (2015c) Dengue and severe dengue. Fact sheet $N^{\circ} 117$. Updated May 2015

WHO (2015d) WHO updates on artemisinin resistance. http://www.who. int/malaria/areas/drug_resistance/updates/en/

WHO (2016) Zika virus. Fact sheet $\mathrm{N}^{\circ} 1$. Updated January 2016

Wiwatanaratanabutr I, Allan S, Linthicum K, Kittayapong P (2010) Strain-specific differences in mating, oviposition, and host-seeking behaviour between Wolbachia-infected and uninfected Aedes albopictus. J Am Mosq Control Assoc 26:265-273

Zsemlye JL, Hancock RG, Foster WA (2005) Analysis of a complex vertical copulatory-courtship display in the yellow fever vector Sabethes chloropterus. Med Vet Entomol 19:276-285 